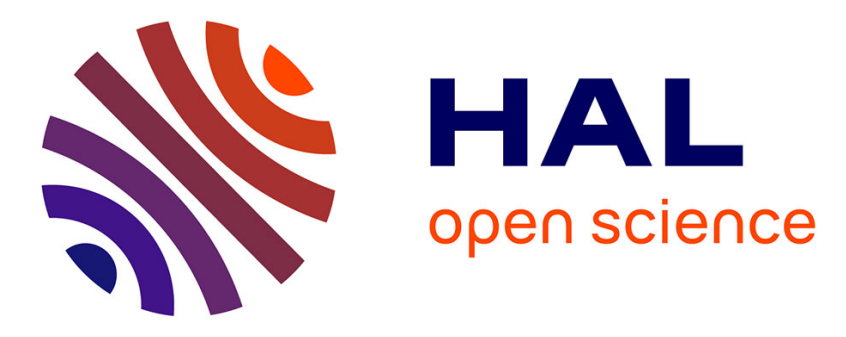

\title{
Genetic tools to improve reproduction traits in dairy cattle
}

Aurelien Capitan, Pauline Michot, Aurélia Baur, Romain Saintilan, Chris Hoze, Damien Valour, François Guillaume, D Boichon, Anne Barbat, Didier

Boichard, et al.

\section{To cite this version:}

Aurelien Capitan, Pauline Michot, Aurélia Baur, Romain Saintilan, Chris Hoze, et al.. Genetic tools to improve reproduction traits in dairy cattle. Reproduction, Fertility and Development, 2015, 27 (1), pp.14-21. 10.1071/RD14379 . hal-01194016

\section{HAL Id: hal-01194016 https://hal.science/hal-01194016}

Submitted on 28 May 2020

HAL is a multi-disciplinary open access archive for the deposit and dissemination of scientific research documents, whether they are published or not. The documents may come from teaching and research institutions in France or abroad, or from public or private research centers.
L'archive ouverte pluridisciplinaire HAL, est destinée au dépôt et à la diffusion de documents scientifiques de niveau recherche, publiés ou non, émanant des établissements d'enseignement et de recherche français ou étrangers, des laboratoires publics ou privés. 


\title{
Genetic tools to improve reproduction traits in dairy cattle
}

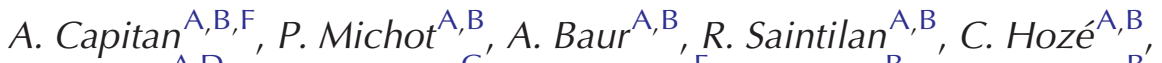 \\ D. Valour ${ }^{\mathrm{A}, \mathrm{D}}$, F. Guillaume $\mathrm{C}^{\prime}$, D. Boichon ${ }^{\mathrm{E}}$, A. Barbat ${ }^{\mathrm{B}}$, D. Boichard ${ }^{\mathrm{B}}$, \\ L. Schibler ${ }^{\mathrm{A}}$ and S. Fritz ${ }^{\mathrm{A}, \mathrm{B}}$ \\ A UNCEIA (Union Nationale des Coopératives d'Elevage et d'Insémination Animale), \\ 149 rue de Bercy, 75012 Paris, France. \\ BINRA (Institut National de la Recherche Agronomique), UMR1313 Génétique Animale et \\ Biologie Intégrative, Domaine de Vilvert, 78352 Jouy-en-Josas, France. \\ CEVOLUTION, 69 rue de la Motte Brûlon, 35706 Rennes, France. \\ DINRA, UMR 1198 Biologie du Développement et Reproduction, Domaine de Vilvert, \\ 78352 Jouy-en-Josas, France. \\ EMIDATEST, Les Nauzes, 81580 Soual, France. \\ FCorresponding author. Email: aurelien.capitan@unceia.fr
}

\begin{abstract}
Fertility is a major concern in the dairy cattle industry and has been the subject of numerous studies over the past 20 years. Surprisingly, most of these studies focused on rough female phenotypes and, despite their important role in reproductive success, male- and embryo-related traits have been poorly investigated. In recent years, the rapid and important evolution of technologies in genetic research has led to the development of genomic selection. The generalisation of this method in combination with the achievements of the AI industry have led to the constitution of large databases of genotyping and sequencing data, as well as refined phenotypes and pedigree records. These resources offer unprecedented opportunities in terms of fundamental and applied research. Here we present five such examples with a focus on reproduction-related traits: (1) detection of quantitative trait loci (QTL) for male fertility and semen quality traits; (2) detection of QTL for refined phenotypes associated with female fertility; (3) identification of recessive embryonic lethal mutations by depletion of homozygous haplotypes; (4) identification of recessive embryonic lethal mutations by mining whole-genome sequencing data; and (5) the contribution of high-density single nucleotide polymorphism chips, whole-genome sequencing and imputation to increasing the power of QTL detection methods and to the identification of causal variants.
\end{abstract}

\section{Introduction}

Fertility is a major concern in the modern dairy cattle industry. Over the past 40 years, the calving rate has decreased steadily as milk production has increased, making low fertility one of the main causes of culling and replacement of cows. Whereas the metabolic demand for milk production negatively impacts reproductive function (Beam and Butler 1999), an indirect response to selection has been shown to account for only half of this decrease (Barbat et al. 2010), suggesting the existence of other factors of an environmental or genetic nature.

Since 2008, the commercial availability of single nucleotide polymorphism (SNP) chips has accelerated the detection of genomic regions associated with production, reproduction, and health traits, and has enabled the development of genomic selection (Goddard and Hayes 2007). This novel tool, which consists of estimating the genetic merit of an animal based on its genotype for a set of genetic markers, has revolutionised animal breeding by allowing the identification of elite breeding stock as early as their birth. Genomic selection is also more accurate than traditional selection for traits with low heritability, such as health or reproductive performance (Calus et al. 2008). These advantages have contributed to a marked increase in genetic gain per year and the clever use of genomic selection has recently enabled us to halt the decrease in female fertility in dairy cattle. Although these first results are encouraging, the road is still long and more efforts have to be made to recover female fertility to an acceptable level. Although reproductive success depends on numerous and complex genetic factors, most of the research has focused surprisingly on female fertility, particularly on rough phenotypes, such as non-return rates (for a review, see Fortes et al. 2013). Much may be expected from genetic studies based on refined phenotypes in females, as well as in males and embryos. In addition, the accumulation of large genotyping and whole-genome sequencing (WGS) datasets is markedly increasing the power of quantitative trait loci (QTL) detection methods and the mining of such databases now enables the detection of recessive embryonic lethal mutations. 
Table 1. Chromosomal regions (quantitative trait loci) associated with male fertility or semen quality traits in dairy cattle breeds ERCR, estimated relative conception rate; SCR, sire conception rate

\begin{tabular}{|c|c|c|c|}
\hline Trait & Breed & Chromosomes & References \\
\hline ERCR & Holstein & $1,4,9,21,27$ & $\begin{array}{l}\text { C. Michot, R. Saintilan, S. Moureaux } \\
\text { and S. Fritz, unpubl. data }\end{array}$ \\
\hline ERCR & Normande & $1,2,5,8,10,15,17,19,22,23,25$ & $\begin{array}{l}\text { C. Michot, R. Saintilan, S. Moureaux } \\
\text { and S. Fritz, unpubl. data }\end{array}$ \\
\hline ERCR & Montbéliarde & $2,3,4,7,9,13,19,29$ & $\begin{array}{l}\text { C. Michot, R. Saintilan, S. Moureaux } \\
\text { and S. Fritz, unpubl. data }\end{array}$ \\
\hline SCR & Holstein & $2,5,18,25,29$ & Peñagaricano et al. (2012) \\
\hline SCR & Holstein & 7 & Lan et al. (2013) \\
\hline ERCR & Holstein & $1,17,19$ & Khatib et al. (2010) \\
\hline \multicolumn{4}{|l|}{ Scrotal circumference } \\
\hline At 12 months & Holstein & $2,4,14,18,19$ & C. Hozé, C. Ponsart and S. Fritz, unpubl. data \\
\hline At 14 months & Holstein & $2,4,15,18,19$ & C. Hozé, C. Ponsart and S. Fritz, unpubl. data \\
\hline Idiopathic subfertility & Fleckvieh & 19 & Pausch et al. (2014) \\
\hline Non-compensatory fertility & Holstein & $3,4,5,6,8,10,12,13,14,15,17,19,22$ & Blaschek et al. (2011) \\
\hline$\%$ Living spermatozoa after thawing & Holstein & 23,27 & Druet et al. (2009) \\
\hline \% Living spermatozoa after thawing & Holstein & $5,7,8,10,17,23$ & $\begin{array}{l}\text { C. Michot, R. Saintilan, S. Moureaux } \\
\text { and S. Fritz, unpubl. data }\end{array}$ \\
\hline Motility & Holstein & $7,11,27$ & Druet et al. (2009) \\
\hline Motility & Holstein & $4,10,11,13,27$ & $\begin{array}{l}\text { C. Michot, R. Saintilan, S. Moureaux } \\
\text { and S. Fritz, unpubl. data }\end{array}$ \\
\hline Sperm volume & Holstein & 15,22 & Druet et al. (2009) \\
\hline Sperm volume & Holstein & $3,14,15,17,22,23,28$ & $\begin{array}{l}\text { C. Michot, R. Saintilan, S. Moureaux } \\
\text { and S. Fritz, unpubl. data }\end{array}$ \\
\hline Sperm concentration & Holstein & $1,3,9,11,13,21,28$ & $\begin{array}{l}\text { C. Michot, R. Saintilan, S. Moureaux } \\
\text { and S. Fritz, unpubl. data }\end{array}$ \\
\hline No. spermatozoa & Holstein & $3,12,21,28$ & $\begin{array}{l}\text { C. Michot, R. Saintilan, S. Moureaux } \\
\text { and S. Fritz, unpubl. data }\end{array}$ \\
\hline
\end{tabular}

Here we present an overview of the achievements and perspectives of bovine genetics with a focus on reproductionrelated traits.

\section{Detection of QTL for male fertility and semen quality traits}

Despite the importance of the male contribution to reproductive success, a surprisingly low number of studies has focused on male fertility traits (Fortes et al. 2013). Yet, as for the female, several parameters that can be used as phenotypes for genome-wide association studies (GWAS) are routinely computed to evaluate male fertility, such as the non-return rate (NRR), estimated relative conception rate (ERCR), sire conception rate (SCR) and male reproductive ability (MRA), which are adjusted for environmental and female genetic effects. Moreover, several parameters are routinely collected by the AI industry to assess semen quality and production. Thus, numerous fine phenotypes have been accumulated for male gametes, including scrotal circumference and compensable (i.e. concentration, motility and morphology) and non-compensable spermatozoid traits that lead to subfertility (i.e. nuclear vacuoles, defective chromatin structure).

The main results obtained regarding male fertility and semen quality traits are summarised in Table 1. Highlights include the identification in the Holstein breed of polymorphisms associated with ERCR in the fibroblast growth factor 2 $(F G F 2)$ and signal transducer and activator of transcription
5A (STAT5A) genes (Khatib et al. 2010) and with SCR in the prophet of Pit 1 (PROP1) gene (Lan et al. 2013). Interestingly, the latter is also associated with milk production, providing molecular evidence for the antagonistic relationship between milk production and fertility. The identification of QTL for scrotal circumference at 12 and 14 months, which is highly correlated with sexual maturity, will allow for the selection for precocity and help breeding schemes to reduce generation intervals (C. Hozé, C. Ponsart and S. Fritz, unpubl. data). In addition, the recent report on idiopathic male subfertility in Fleckvieh caused by a loss-of-function mutation in a nondescript transmembrane protein 95 (TMEM95) essential for fertilisation (Pausch et al. 2014) exemplifies the important contribution that such studies can have to the annotation of the function of unknown genes. Finally, the identification of QTL (Druet et al. 2009) and candidate mutations (C. Michot, R. Saintilan, S. Moureaux S. and Fritz, unpubl. data) for semen quality, sperm volume and survival after thawing and five morphology traits also represent a unique opportunity to dissect the molecular basis of the global phenotypes analysed so far.

\section{Detection of QTL for refined phenotypes associated with female fertility}

As mentioned previously, there have been numerous studies based on global phenotypes and, more recently, on refined phenotypes in female fertility (for a review, see Fortes et al. 
Table 2. Main groups of markers (quantitative trait loci) associated with the total number of embryos and the number of viable embryos according to A. Baur, R. Saintilan, F. Guillaume, D. Boichon and S. Fritz (unpubl. data)

Ntot, total number of embryos; Viab, number of viable embryos; UMD3, the UMD3 version of the bovine genome assembly; TANC1, Tetratricopeptide Repeat, Ankyrin Repeat And Coiled-Coil Domain-Containing Protein 1; DAPL1, Death Associated Protein-Like 1; PKP4, Plakophilin 4; EMR1, Egf-Like Module Containing, Mucin-Like, Hormone Receptor-Like 1; VAV1, Vav 1 Guanine Nucleotide Exchange Factor; SH2D3A, SH2 Domain Containing 3A; TRIP10, Thyroid Receptor-Interacting Protein 10; GPR108, G Protein-Coupled Receptor 108; C3, Complement Component 3; TNFSF14, Tumor Necrosis Factor (Ligand) Superfamily Member 14; TUBB4A, tubulin beta 4A class Iva; PLEK2, Pleckstrin 2; TMEM229B, Transmembrane Protein 229B; PLEKHH1, Pleckstrin Homology Domain Containing, Family H (With MyTH4 Domain) Member 1; PIGH, Phosphatidylinositol Glycan Anchor Biosynthesis, Class H; ARG2, Arginase 2; VTI1B, Vesicle Transport Through Interaction With T-SNAREs 1B; PPPIR21, Protein Phosphatase 1, Regulatory Subunit 21; STON1, Stonin 1; GTF2A1L: General Transcription Factor IIA, 1-Like; LHCGR, Luteinizing Hormone/Choriogonadotropin Receptor; FSHR, Follicle Stimulating Hormone Receptor; SPAG1: Sperm Associated Antigen 1; POLR2K, Polymerase (RNA) II (DNA Directed) Polypeptide K, 7.0kDa; FBXO43, F-Box Protein 43; RGS22, Regulator Of G-Protein Signaling 22; COX6C, Cytochrome C Oxidase Subunit VIc; VPS13B, Vacuolar Protein Sorting 13 Homolog B; CES5A, Carboxylesterase 5A; BREH1, Bos taurus retinyl ester hydrolase type 1; NUP93, Nucleoporin 93kDa; SLC12A3, Solute Carrier Family 12 (Sodium/Chloride Transporter), Member 3; HERPUD1, Homocysteine-Inducible, Endoplasmic Reticulum Stress-Inducible, Ubiquitin-Like Domain Member 1; $P A R V G$, Parvin, Gamma; LDOC1L, Leucine Zipper, Down-Regulated In Cancer 1-Like; PRR5, Proline Rich 5 (Renal); ARHGAP8, Rho GTPase Activating Protein 8; ZMYND8, Zinc Finger, MYND-Type Containing 8; NCOA3, Nuclear Receptor Coactivator 3; SULF2, Sulfatase 2

\begin{tabular}{lcccll}
\hline Trait & Chromosome & Position on UMD3 $(\mathrm{Mb})$ & Sum of $\gamma$ probability & Effect & Genes in the vicinity $( \pm 250 \mathrm{~kb})$ of the top marker \\
\hline Ntot & 2 & 37.6 & 0.55 & 0.16 & TANC1, DAPL1, PKP4 \\
Ntot & 7 & 19.0 & 0.50 & 0.08 & EMR1, VAV1, SH2D3A, TRIP10, GPR108, C3, TNFSF14, TUBB4A \\
Ntot & 10 & 79.9 & 0.73 & 0.06 & $P L E K 2, T M E M 229 B, P L E K H H 1, P I G H, A R G 2$, VTI1B \\
Ntot & 11 & 30.9 & 1.18 & 0.10 & $P P P 1 R 21, S T O N 1, G T F 2 A 1 L, L H C G R, F S H R$ \\
Ntot & 14 & 66.6 & 0.49 & 0.09 & SPAG1, POLR2K, FBXO43, RGS22, COX6C, VPS13B \\
Ntot & 18 & 24.9 & 0.69 & 0.15 & CES5A, BREH1, NUP93, SLC12A3, HERPUD1 \\
Ntot & 29 & 31.4 & 0.56 & 0.15 & None \\
Viab & 5 & 115.8 & 1.82 & 0.07 & PARVG, LDOC1L, PRR5, ARHGAP8 \\
Viab & 13 & 76.8 & 0.75 & 0.04 & ZMYND8, NCOA3, SULF2 \\
\hline
\end{tabular}

2013). Because of technical aspects, efforts to refine the phenotypes have focused mainly on the fine dissection of periods of times (e.g. gestation length or duration of anoestrus) or in the fine monitoring of gestation (Lefebvre et al. 2011) rather than in assessing the quality and/or quantity of oocytes (and embryos) in large cohorts of animals. The main parameters evaluated from conception to weaning are, to date, age at puberty and at first conception, ovulation rates, fertilisation failure, number of inseminations, embryo death, fetal losses, gestation length, duration of postpartum anoestrus, fertility and interval between first and last service (D. Valour, P. Michot, R. Lefebvre, E. Sellem, A. Bonnet, J. Dupont, R. Dalbies-Tran, S. Uzbekova, A. Capitan, S. Fritz, C. Ponsart and L. Schibler, unpubl. data). It is worth noting that whereas these traits are recorded in cows, the detection of QTL is, in most cases, performed in AI sires after the transformation of theses phenotypes in daughter yield deviations.

Nevertheless, times are changing and the opening up of the genomic selection service for female combined with the widespread use of embryo transfer is resulting in the creation of large databases of females with both genotype and refined phenotypes available, in addition to the regular phenotypes mentioned above. Recently, our team ran a pilot study on a panel of 4067 Holstein females with records available for the total number of embryos (Ntot) and the number of viable embryos (Viab) produced after superovulation protocols $($ mean $=1.4$ protocols per animal; A. Baur, R. Saintilan, F. Guillaume, D. Boichon and S. Fritz, unpubl. data). After adjusting the data for different non-genetic effects (i.e. parity, superovulation in farm or station, breeding companies and team of operators), relatively high heritabilities were obtained for Ntot (0.32) and Viab (0.19), suggesting the existence of genetic variants with substantial effects on these traits. Then, a Bayesian sparse linear mixed model (BSLMM) was used to identify markers significantly associated with both phenotypes and to estimate their effects to implement genomic selection. Seven bona fide QTL for Ntot and two for Viab were detected (Table 2).

Remarkably, receptors for LH and GSH (LHCGR and FSHR, respectively), which are the molecules injected to induce superovulation of females, were collocated with the most significant QTL for Ntot. The ongoing identification of the causative mutations for these QTL will undoubtedly greatly increase our knowledge of folliculogenesis and embryonic development. In parallel, a pilot genomic selection has been implemented using 861 markers for Ntot and 875 for Viab that explains $40 \%$ of the genetic variance for each trait. First results (A. Baur, R. Saintilan, F. Guillaume, D. Boichon and S. Fritz, unpubl. data) are encouraging and their forthcoming use by the breeding schemes should progressively increase their efficiency.

\section{Mapping of recessive embryonic lethal mutations by depletion of homozygous haplotypes}

Because of the high selection intensity and reduced size of the effective population in dairy cattle, typical breeds display an average inbreeding rate of approximately $1 \%$ per generation (Boichard et al. 1996; Miglior 2000). Such an inbreeding trend is favourable to the expression of recessive defects and nearly all dairy cattle breeds are characterised by regular emergences of genetic defects, such as factor XI deficiency (Gentry and Black 1980; Marron et al. 2004), citrullinaemia (Harper et al. 1988; 
Table 3. Haplotypes and genes associated with prenatal death in cattle

BTA, Bos Taurus chromosome; UMD3, the UMD3 version of the bovine genome assembly; RNASEH2B, Ribonuclease H2, Subunit B; FANCI, Fanconi Anemia, Complementation Group I; APAF1, Apoptotic Peptidase Activating Factor 1; SMC2, Structural Maintenance Of Chromosomes 2; GART, Phosphoribosylglycinamide Formyltransferase, Phosphoribosylglycinamide Synthetase, Phosphoribosylaminoimidazole Synthetase; CWC15, CWC15 Spliceosome-Associated Protein Homolog (S. Cerevisiae); SLC37A2, Solute Carrier Family 37 (Glucose-6-Phosphate Transporter), Member 2

\begin{tabular}{|c|c|c|c|c|c|}
\hline Breed & $\begin{array}{l}\text { Haplotype } \\
\text { name }\end{array}$ & BTA & $\begin{array}{c}\text { Region on } \\
\text { UMD3 }(\mathrm{Mb})\end{array}$ & Gene name & Reference \\
\hline Ayrshire & AH1 & 17 & $65.9-66.2$ & & Cooper et al. (2014) \\
\hline Brown Swiss & $\mathrm{BH} 2$ & 19 & $10.1-11.1$ & & Schwarzenbacher et al. (2012) \\
\hline $\begin{array}{l}\text { Finnish Ayrshire } \\
\text { Swedish Red }\end{array}$ & & 12 & $20.1-20.7$ & RNASEH2B & Kadri et al. (2014) \\
\hline \multirow{7}{*}{ Holstein } & HH1 & 5 & 63.1 & $A P A F 1$ & VanRaden et al. (2011); Adams et al. (2012); Fritz et al. (2013) \\
\hline & $\mathrm{HH} 2$ & 1 & $94.8-96.6$ & & VanRaden et al. (2011) \\
\hline & HH3 & 8 & 95.4 & $S M C 2$ & $\begin{array}{l}\text { VanRaden et al. (2011); Fritz et al. (2013); Sahana et al. (2013); } \\
\text { McClure et al. (2014); Daetwyler et al. (2014) }\end{array}$ \\
\hline & $\mathrm{HH} 4$ & 1 & 1.3 & GART & Fritz et al. (2013) \\
\hline & HH5 & 9 & $91.8-93.8$ & & http://holsteinworld.com/story.php?id =9160 (accessed 1 July 2014) \\
\hline & & 7 & $34.6-36.1$ & & Sahana et al. (2013) \\
\hline & & 11 & $55.3-63.8$ & & Sahana et al. (2013) \\
\hline Jersey & JH1 & 15 & 15.7 & $C W C 15$ & VanRaden et al. (2011); Sonstegard et al. (2013) \\
\hline \multirow[t]{2}{*}{ Montbéliarde } & MH1 & 19 & $27.6-29.4$ & & Fritz et al. (2013) \\
\hline & MH2 & 29 & 28.9 & SLC37A2 & Fritz et al. (2013) \\
\hline \multirow[t]{4}{*}{ Normande } & NH1 & 24 & $38.1-39.2$ & & Fritz et al. (2013) \\
\hline & $\mathrm{NH} 2$ & 1 & $45.7-146.8$ & & Fritz et al. (2013) \\
\hline & NH5 & 7 & $3.6-4.6$ & & Fritz et al. (2013) \\
\hline & NH6 & 15 & $59.8-61.1$ & & Fritz et al. (2013) \\
\hline
\end{tabular}

Dennis et al. 1989), deficiency of uridine monophosphate synthase (DUMPS; Schwenger et al. 1993), bovine leucocyte adhesion deficiency (BLAD; Shuster et al. 1992), complex vertebral malformation (CVM; Agerholm et al. 2001), syndactyly (Duchesne et al. 2006) or brachyspina (Agerholm and Peperkamp 2007; Charlier et al. 2012), in Holstein. In recent years, the availability of high-density (HD) SNP chips and the use of homozygosity mapping have enabled the mapping of novel recessive defects in a very short period of time with as few as five to 10 cases (Lander and Botstein 1987; Charlier et al. 2008). However, this approach involves the detection of calves showing clinical manifestations and, de facto, except defects ending sporadically in late term abortion (e.g. citrullinaemia, CVM or brachyspina), most recessive embryonic lethal (EL) variants are missed because of the absence of observable cases.

More recently, following the initiative of VanRaden et al. (2011), a novel strategy has been used to detect EL. This strategy relies on the screening of medium-density SNP chip genotyping data (i.e. 50 000-80 000 markers) from hundreds of thousands of animals generated for genomic selection for haplotypes (i.e. sets of consecutive SNP) that are never observed in the homozygous state in live animals or that display a significant depletion in homozygotes. Because this strategy enables the mapping of recessive defects without assumption on the phenotype of homozygous animals, a second step consisting of a comparison of the conception rate in at-risk mating (i.e. between a bull carrying a haplotype and daughters of a bull carrying the same haplotype) and in the general population is required to distinguish EL from other recessive defects resulting in the absence or depletion of homozygous animals in the genomic selection database (e.g. postnatal lethality, malformation or simply animals that do not comply with the breed standard).

Application of this new strategy resulted in the detection of EL in each of the breeds investigated and, in association with whole-genome or exome sequencing, in the identification of causative variants for several of them (Table 3 ).

Because the power of the method depends on the amount of genotyping data and on the frequency of the haplotypes in the population, it is not rare that in addition to common EL distinct additional EL are detected in subpopulations of the same breeds as observed in the Holstein. Two main reasons can be invoked to explain this observation. First, the absence of complete linkage disequilibrium between EL mutations and surrounding haplotypes because of the segregation of ancestral non-mutated haplotypes markedly reduces the power of the method in certain populations. Second, differences in allele frequencies are generally observed between populations and rare EL are missed because of power limitation. Indeed, the detection of a haplotype with a frequency of $1 \%$ in the population basically requires the absence of homozygotes among 100000 animals (i.e. 0 vs 10 expected) to be significant. Remarkably, as reported for a $660-\mathrm{kb}$ deletion in Nordic red breeds (Kadri et al. 2014), which has been shown to increase milk yield in heterozygotes, the frequency of EL can rise up to 


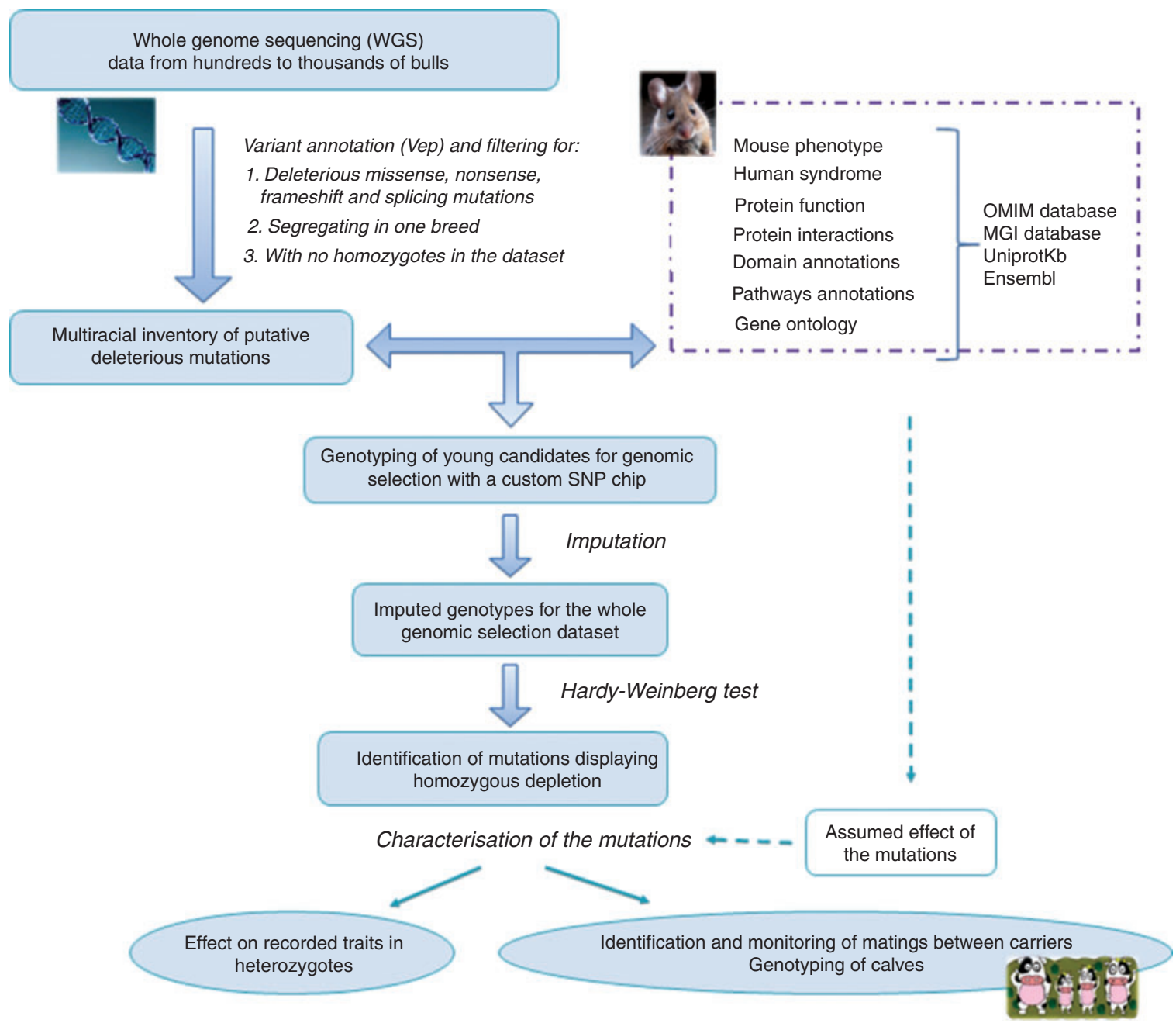

Fig. 1. Identification of recessive lethal mutations from whole genome sequencing data.

$25 \%$ because of balancing selection and thus cause as high as a $6.25 \%$ decrease in conception rate.

In this context, with multiple EL per breed and/or EL with high frequencies, drastic elimination of all carriers as traditionally practiced with recessive defects would further reduce the effective size of the population and have marked consequences on genetic progress. Thus, breeding schemes have implemented a gradual counterselection of these deleterious haplotypes and/ or mutations as well as systems to manage matings to progressively regain satisfactory levels of female fertility.

\section{Identification of recessive lethal mutations from WGS data}

As discussed above, although the screening for homozygous haplotype depletion has proven a very efficient tool to identify yet unknown EL, this method has its own limitations. The availability of WGS data from hundreds or thousands of animals generated since 2012 in the framework of genomic selection programs has enabled the development of another strategy named 'reverse genetic screen' or 'from sequence to consequence' (Charlier et al. 2014; P. Michot, D. Boichard and A. Capitan, unpubl. data; Fig. 1). First, it consists of identifying variants that are: (1) predicted to be deleterious; (2) never observed in the homozygous state in the WGS data; and (3) breed specific (most genetic defects are indeed recent and breed specific because deleterious mutations predating the development of breeds are assumed to have been eliminated by purifying selection). Then, public databases (e.g. Mouse Genome Informatics, http://www.informatics.jax.org/, accessed 1 July 2014; Online Mendelian Inheritance in Man, www.omim. org/, accessed 1 July 2014; Uniprot, http://www.uniprot.org/, accessed 1 July 2014) are mined to predict the biological consequences of these mutations and to reduce the list of variants of mutations in genes for which an insufficiency is EL. Mutations found in genes with unknown function give a unique opportunity to annotate them and thus may also be investigated.

Hundreds to thousands of these polymorphisms are thereafter genotyped using custom SNP chips. In France and in other European countries, these polymorphisms are added to the Illumina EuroG10K SNP Chip (Illumina, San Diego, CA, 
USA), which is routinely used for genomic selection and has been developed in the framework of the Eurogenomics consortium. This enables the free genotyping of large panels of animals ( $\sim 8000$ per month for France only) and makes it possible to predict the status of the hundreds of thousands of animals that have been genotyped before with medium-density SNP chips after imputation (see below). Hardy-Weinberg tests are then computed and homozygous depletion investigated. It is worth noting that for the rarest polymorphisms the number of homozygous animals expected in the population studied is often close to zero, which does not permit to conclude to a significant depletion of homozygous animals. In such cases, because the genotype of all the AI bulls for each of these mutations is known and all the AI performed in France as well as the pedigree of the cows are recorded, databases are mined to identify at-risk gestations among the millions of matings performed each year. This enables: (1) estimation of the effect of the mutations on fertility by comparing NNR between at-risk mating and the rest of the matings; and (2) identification of calves to be genotyped at birth to verify homozygous depletion and phenotype homozygous animals if the defect is not completely EL.

The first results are fulfilling the expectations and tens of novel EL are currently under characterisation in various breeds (Charlier et al. 2014; P. Michot, D. Boichard and A. Capitan, unpubl. data).

\section{Contributions of HD SNP chips, WGS and imputation to increasing the power of QTL detection methods and identification of causal variants}

In genetic studies, two main strategies are used to increase the power of QTL detection and refine QTL intervals: (1) increasing population size; and (2) marker density. Because increasing population size represents a substantial effort of phenotyping, sampling and genotyping, this strategy is often restricted to studies on low heritable traits or traits that are not routinely phenotyped. For other types of traits, the size of the population (i.e. tens of thousands of animals) is generally sufficient to map QTL in relatively small intervals (i.e. between $1 \mathrm{Mb}$ and $500 \mathrm{~kb}$ with medium-density chips containing 50 000-80 000 markers). In 2012, the commercial availability of HD SNP chips containing 700000-800000 markers allowed for further fine mapping of these QTL after imputation. Imputation consists of genotyping, with HD chips, a subset of animals that is highly linked with the population (usually hundreds of founder sires) and then using linkage disequilibrium and pedigree information to predict the genotype for this novel marker panel of hundreds of thousands of animals previously genotyped with mediumdensity chips. In summary, imputation leads to a marked increase in both the size of the population and the density of markers in silico. Aside from imputation strategies, HD chips containing for the first time markers from the $\mathrm{Y}$ chromosome have also proven useful by enabling the discovery of segments from this chromosome in the genome of females with a reduced pregnancy rate (McDaneld et al. 2012). The availability of WGS and the imputation 'up to the sequence' is now opening a new era in QTL detection. Indeed, large panels of animals genotyped in silico for most of the genetic variants found in their breeds enable, for the first time, the identification of causative mutations without prior assumption on their function or localisation (Marchini and Howie 2010; Daetwyler et al. 2014; Brøndum et al. 2014). Interestingly, most of the polymorphisms that are most associated with quantitative traits are located in the promoter region of genes. There is no doubt that their functional characterisation in the near future will greatly improve our knowledge of the regulation of gene expression and the biological processes underlying quantitative traits.

\section{Conclusion}

There are significant and rapid advances being made in technology in the field of genetics. Because of the importance of dairy and beef production, cattle have been one of the first livestock species to benefit from these innovations, leading to the development of genomic selection. Consequently, the achievements of the AI industry and the generalisation of genomic selection have led to the construction of large databases of genotyping and sequencing data, as well as phenotype and pedigree records. These resources offer unprecedented opportunities for both fundamental and applied research. Their clever use is under way and novel tools are being developed to improve selection efficiency, especially for low or medium heritable traits, such as reproduction, in dairy cattle.

\section{Acknowledgements}

The authors are grateful to the staff of the breeding centres at EVOLUTION and MIDATEST for kindly providing phenotypic records for different studies. The authors also acknowledge their colleagues from the INRA UMT3G and from the 1000 bull genome consortium project for sharing WGS data and for useful discussions. Finally, the authors thank Apis Gene and the French National Research Agency for funding most of the research we are conducting.

\section{References}

Adams, H. A., Sonstegard, T., VanRaden, P. M., Null, D. J., Van Tassell, C. P., and Lewin, H. (2012). Identification of a nonsense mutation in APAF1 that is causal for a decrease in reproductive efficiency in dairy cattle. In 'Plant Anim Genome XX Conference, San Diego, CA, USA'. Abstract P0555. (Scherago International: Jersey City, NJ.)

Agerholm, J. S., and Peperkamp, K. (2007). Familial occurrence of Danish and Dutch cases of the bovine brachyspina syndrome. BMC Vet. Res. $\mathbf{3}$, 8. doi:10.1186/1746-6148-3-8

Agerholm, J. S., Bendixen, C., Andersen, O., and Arnbjerg, J. (2001) Complex vertebral malformation in Holstein calves. J. Vet. Diagn. Invest. 13, 283-289. doi:10.1177/104063870101300401

Barbat, A., Le Mézec, P., Ducrocq, V., Mattalia, S., Fritz, S., Boichard, D., Ponsart, C., and Humblot, P. (2010). Female fertility in French dairy breeds: current situation and strategies for improvement. J. Reprod. Dev. 56, S15-S21. doi:10.1262/JRD.1056S15

Beam, S. W., and Butler, W. R. (1999). Effects of energy balance on follicular development and first ovulation in postpartum dairy cows J. Reprod. Fertil. Suppl. 54, 411-424.

Blaschek, M., Kaya, A., Zwald, N., Memili, E., and Kirkpatrick, B. W. (2011). A whole-genome association analysis of noncompensatory fertility in Holstein bulls. J. Dairy Sci. 94, 4695-4699. doi:10.3168/ JDS.2010-3728

Boichard, D., Maignel, L., and Verrier, E. (1996). Analyse généalogique des races bovines laitières françaises. INRA Prod. Anim. 9, 323-335. 
Brøndum, R. F., Guldbrandtsen, B., Sahana, G., Lund, M. S., and Su, G. (2014). Strategies for imputation to whole genome sequence using a single or multi-breed reference population in cattle. BMC Genomics $\mathbf{1 5}$, 728. doi:10.1186/1471-2164-15-728

Calus, M. P., Meuwissen, T. H., de Roos, A. P., and Veerkamp, R. F. (2008). Accuracy of genomic selection using different methods to define haplotypes. Genetics 178, 553-561. doi:10.1534/GENETICS.107.080838

Charlier, C., Coppieters, W., Rollin, F., Desmecht, D., Agerholm, J. S., Cambisano, N., Carta, E., Dardano, S., Dive, M., Fasquelle, C., Frennet, J. C., Hanset, R., Hubin, X., Jorgensen, C., Karim, L., Kent, M., Harvey, K., Pearce, B. R., Simon, P., Tama, N., Nie, H., Vandeputte, S., Lien, S., Longeri, M., Fredholm, M., Harvey, R. J., and Georges, M. (2008). Highly effective SNP-based association mapping and management of recessive defects in livestock. Nat. Genet. 40, 449-454. doi:10.1038/NG.96

Charlier, C., Agerholm, J. S., Coppieters, W., Karlskov-Mortensen, P., Li, W., de Jong, G., Fasquelle, C., Karim, L., Cirera, S., Cambisano, N., Ahariz, N., Mullaart, E., Georges, M., and Fredholm, M. (2012). A deletion in the bovine FANCI gene compromises fertility by causing fetal death and brachyspina. PLOS ONE 7, e43085. doi:10.1371/ JOURNAL.PONE.0043085

Charlier, C., Li, W., Harland, C., Littlejohn, M., Creagh, F., Keehan, M., Druet, T., Coppieters, W., Spelman, R., and Georges, M. (2014). NGSbased reverse genetic screen reveals loss-of-function variants compromising fertility in cattle. In 'Proceedings of the 10th World Congress of Genetics Applied to Livestock Production, Vancouver, Canada'. Available at http://www.wcgalp.com/ [verified 29 August 2014].

Cooper, T. A., Wiggans, G. R., Null, D. J., Hutchison, J. L., and Cole, J. B. (2014). Genomic evaluation, breed identification, and discovery of a haplotype affecting fertility for Ayrshire dairy cattle. J. Dairy Sci. 97, 3878-3882. doi:10.3168/JDS.2013-7427

Daetwyler, H. D., Capitan, A., Pausch, H., Stothard, P., van Binsbergen, R., Brøndum, R. F., Liao, X., Djari, A., Rodriguez, S. C., Grohs, C., Esquerré, D., Bouchez, O., Rossignol, M. N., Klopp, C., Rocha, D., Fritz, S., Eggen, A., Bowman, P. J., Coote, D., Chamberlain, A. J., Anderson, C., VanTassell, C. P., Hulsegge, I., Goddard, M. E., Guldbrandtsen, B., Lund, M. S., Veerkamp, R. F., Boichard, D. A., Fries, R., and Hayes, B. J. (2014). Whole-genome sequencing of 234 bulls facilitates mapping of monogenic and complex traits in cattle. Nat. Genet. 46, 858-865. doi:10.1038/NG.3034

Dennis, J. A., Healy, P. J., Beaudet, A. L., and O'Brien, W. E. (1989). Molecular definition of bovine argininosuccinate synthetase deficiency. Proc. Natl Acad. Sci. USA 86, 7947-7951. doi:10.1073/PNAS.86.20.7947

Druet, T., Fritz, S., Sellem, E., Basso, B., Gérard, O., Salas-Cortes, L., Humblot, P., Druart, X., and Eggen, A. (2009). Estimation of genetic parameters and genome scan for 15 semen characteristics traits of Holstein bulls. J. Anim. Breed. Genet. 126, 269-277. doi:10.1111/ J.1439-0388.2008.00788.X

Duchesne, A., Gautier, M., Chadi, S., Grohs, C., Floriot, S., Gallard, Y., Caste, G., Ducos, A., and Eggen, A. (2006). Identification of a doublet missense substitution in the bovine LRP4 gene as a candidate causal mutation for syndactyly in Holstein cattle. Genomics 88, 610-621. doi:10.1016/J.YGENO.2006.05.007

Fortes, M. R., Deatley, K. L., Lehnert, S. A., Burns, B. M., Reverter, A., Hawken, R. J., Boe-Hansen, G., Moore, S. S., and Thomas, M. G. (2013). Genomic regions associated with fertility traits in male and female cattle: advances from microsatellites to high-density chips and beyond. Anim. Reprod. Sci. 141, 1-19. doi:10.1016/J.ANIREPROSCI.2013.07.002

Fritz, S., Capitan, A., Djari, A., Rodriguez, S. C., Barbat, A., Baur, A., Grohs, C., Weiss, B., Boussaha, M., Esquerré, D., Klopp, C., Rocha, D., and Boichard, D. (2013). Detection of haplotypes associated with prenatal death in dairy cattle and identification of deleterious mutations in GART, SHBG and SLC37A2. PLoS ONE 8, e65550. doi:10.1371/ JOURNAL.PONE.0065550
Gentry, P. A., and Black, W. D. (1980). Prevalence and inheritance of factor XI (plasma thromboplastin antecedent) deficiency in cattle. J. Dairy Sci. 63, 616-620. doi:10.3168/JDS.S0022-0302(80)82980-8

Goddard, M. E., and Hayes, B. J. (2007). Genomic selection. J. Anim. Breed. Genet. 124, 323-330. doi:10.1111/J.1439-0388.2007.00702.X

Harper, P. A., Healy, P. J., Dennis, J. A., and Martin, A. B. (1988). Ultrastructural findings in citrullinaemia in Holstein-Friesian calves. Acta Neuropathol. 76, 306-310. doi:10.1007/BF00687780

Kadri, N. K., Sahana, G., Charlier, C., Iso-Touru, T., Guldbrandtsen, B., Karim, L., Nielsen, U. S., Panitz, F., Aamand, G. P., Schulman, N., Georges, M., Vilkki, J., Lund, M. S., and Druet, T. (2014). A 660-Kb deletion with antagonistic effects on fertility and milk production segregates at high frequency in Nordic Red cattle: additional evidence for the common occurrence of balancing selection in livestock. PLoS Genet. 10, e1004049. doi:10.1371/JOURNAL.PGEN.1004049

Khatib, H., Monson, R. L., Huang, W., Khatib, R., Schutzkus, V., Khateeb, H., and Parrish, J. J. (2010). Short communication: validation of in vitro fertility genes in a Holstein bull population. J. Dairy Sci. 93, 2244-2249. doi:10.3168/JDS.2009-2805

Lan, X. Y., Penagaricano, F., DeJung, L., Weigel, K. A., and Khatib, H. (2013). Short communication: a missense mutation in the PROPI (prophet of Pit 1) gene affects male fertility and milk production traits in the US Holstein population. J. Dairy Sci. 96, 1255-1257. doi:10.3168/ JDS.2012-6019

Lander, E. S., and Botstein, D. (1987). Homozygosity mapping: a way to map human recessive traits with the DNA of inbred children. Science 236, 1567-1570. doi:10.1126/SCIENCE. 2884728

Lefebvre, R., Fritz, S., Ledoux, D., Gatien, J., Genestout, L., Rossignol, M. N., Grimard, B., Boichard, D., Humblot, P., and Ponsart, C. (2011). GENIFER cartographie fine et effets de QTL de fertilité en race bovine Holstein. In '18èmes Rencontres Recherches Ruminants, Paris'. (Ed. Institut de l'Elevage.) p. 415 [Abstract]. (Rencontres autour des Recherches sur les Ruminants: Paris.)

Marchini, J., and Howie, B. (2010). Genotype imputation for genome-wide association studies Nat. Rev. Genet. 11, 499-511. doi:10.1038/ NRG2796

Marron, B. M., Robinson, J. L., Gentry, P. A., and Beever, J. E. (2004). Identification of a mutation associated with factor XI deficiency in Holstein cattle. Anim. Genet. 35, 454-456. doi:10.1111/J.1365-2052. 2004.01202.X

McClure, M. C., Bickhart, D., Null, D., Vanraden, P., Xu, L., Wiggans, G., Liu, G., Schroeder, S., Glasscock, J., Armstrong, J., Cole, J. B., Van Tassell, C. P., and Sonstegard, T. S. (2014). Bovine exome sequence analysis and targeted SNP genotyping of recessive fertility defects $\mathrm{BH} 1$, $\mathrm{HH} 2$, and $\mathrm{HH} 3$ reveal a putative causative mutation in SMC2 for $\mathrm{HH} 3$. PLoS ONE 9, e92769. doi:10.1371/JOURNAL.PONE.0092769

McDaneld, T. G., Kuehn, L. A., Thomas, M. G., Snelling, W. M., Sonstegard, T. S., Matukumalli, L. K., Smith, T. P., Pollak, E. J., and Keele, J. W. (2012). Y are you not pregnant: identification of Y chromosome segments in female cattle with decreased reproductive efficiency. J. Anim. Sci. 90, 2142-2151. doi:10.2527/JAS.2011-4536

Miglior, F. (2000). Impact of inbreeding: managing a declining Holstein gene pool. In 'Proceedings of the 10th World Holstein Friesian Federation Conference, Sydney, Australia'. pp. 108-113.

Pausch, H., Kölle, S., Wurmser, C., Schwarzenbacher, H., Emmerling, R., Jansen, S., Trottmann, M., Fuerst, C., Götz, K. U., and Fries, R. (2014). A nonsense mutation in TMEM95 encoding a nondescript transmembrane protein causes idiopathic male subfertility in cattle. PLoS Genet. 10, e1004044. doi:10.1371/JOURNAL.PGEN.1004044

Peñagaricano, F., Weigel, K. A., and Khatib, H. (2012). Genome-wide association study identifies candidate markers for bull fertility in Holstein dairy cattle. Anim. Genet. 43, 65-71. doi:10.1111/J.13652052.2012.02350.X 
Sahana, G., Nielsen, U. S., Aamand, G. P., Lund, M. S., and Guldbrandtsen, B. (2013). Novel harmful recessive haplotypes identified for fertility traits in nordic holstein cattle. PLOS ONE 8, e82909. doi:10.1371/ JOURNAL.PONE.0082909

Schwarzenbacher, H., Fuerst, C., Fuerst-Waltl, B., and Dolezal, M. (2012). A genome-wide search for harmful recessive haplotypes in Brown Swiss and Fleckvieh cattle. In '63rd EAAP Meeting Book of Abstracts, Bratislava, Slovakia'. p. 170. (Wageningen Academic Publishers: Wageningen, The Netherlands.)

Schwenger, B., Schöber, S., and Simon, D. (1993). DUMPS cattle carry a point mutation in the uridine monophosphate synthase gene. Genomics 16, 241-244. doi:10.1006/GENO.1993.1165

Shuster, D. E., Kehrli, M. E., Ackermann, M. R., and Gilbert, R. O. (1992) Identification and prevalence of a genetic defect that causes leukocyte adhesion deficiency in Holstein cattle. Proc. Natl Acad. Sci. USA 89, 9225-9229. doi:10.1073/PNAS.89.19.9225

Sonstegard, T. S., Cole, J. B., VanRaden, P. M., Van Tassell, C. P., Null, D. J., Schroeder, S. G., Bickhart, D., and McClure, M. C. (2013). Identification of a nonsense mutation in $\mathrm{CWC15}$ associated with decreased reproductive efficiency in Jersey cattle. PLOS ONE 8, e54872. doi:10.1371/JOURNAL.PONE.0054872

VanRaden, P. M., Olson, K. M., Null, D. J., and Hutchison, J. L. (2011) Harmful recessive effects on fertility detected by absence of homozygous haplotypes. J. Dairy Sci. 94, 6153-6161. doi:10.3168/JDS 2011-4624 